\title{
Extração enzimática das proteínas da farinha de arroz
}

\author{
Enzymatic extraction of proteins from rice flour
Claudia Regina VIEIRA ${ }^{1}$, Carlos de Oliveira LOPES Jr. ${ }^{1}$, Camila Salles RAMOS ${ }^{1}$, Michely CAPOBIANGO ${ }^{1}$, Marialice Pinto Coelho SILVESTRE ${ }^{1 \star}$

\section{Resumo}

O presente trabalho teve como objetivo extrair enzimaticamente as proteínas de uma farinha comercial de arroz. Visando aumentar o Rendimento de Extração Protéica (REP), os seguintes parâmetros foram avaliados: tipo de enzima (protease alcalina e neutra); temperatura $\left(40,50\right.$ e $\left.60^{\circ} \mathrm{C}\right) ; \mathrm{pH}(9,5,10,5$ e 11,0); tratamento físico da amostra (sem tratamento, ultra-turrax a $16.000 \mathrm{rpm}$ e ultra-som a $120 \mathrm{~W}$, ambos por 5, 10 e 15 minutos); relação Enzima:Substrato (E:S) de 5:100 e 10:100; e concentração inicial de matéria-prima (1:3, 1:5 e 1:10 p/v). Os teores de proteínas da farinha de arroz e dos resíduos foram determinados para o cálculo do REP. Os resultados mostraram que a melhor condição de extração protéica, que levou ao maior REP, foi a que empregou a concentração inicial de matéria-prima a 1:10 (p/v), sem tratamento físico, com pH 10,5, com a protease alcalina na relação E:S de 10:100, a $50{ }^{\circ} \mathrm{C}$, tendo atingido um REP de $63,4 \%$.

Palavras-chave: arroz; enzimas; extração; proteínas; rendimento.

\begin{abstract}
The enzymatic extraction of proteins from a commercial rice flour was studied in this work. In order to increase the Protein Extraction Yield (PEY), the following parameters were evaluated: enzyme type (alkaline and neutral protease); temperature (40, 50 and $60{ }^{\circ} \mathrm{C}$ ); $\mathrm{pH}$ (9.5, 10.5 and 11.0); physical treatment of the sample (no treatment; Ultra-Turrax at $16.000 \mathrm{rpm}$ and ultrasound at $120 \mathrm{~W}$, both for 5, 10 and 15 minutes); enzyme:substrate ratio (E:S) of 5:100 and 10:100 and initial concentration of raw material (1:3, 1:5 and 1:10 w/v). The PEY was calculated using the protein contents of rice flour and the extraction residues. The results showed that the best condition for protein extraction, which gave the highest PEY (63.4\%), was that using an initial concentration of raw material of 1:10 (w/v), no physical treatment, $\mathrm{pH} 10.5$, the alkaline protease, an E:S of 10:100, at $50^{\circ} \mathrm{C}$.
\end{abstract}

Keywords: rice; enzymes; extraction; protein; yield.

\section{Introdução}

Os grãos de cereais constituem uma fonte valiosa de proteínas para a alimentação humana. No Brasil, os cereais mais importantes, econômica e nutricionalmente, são o trigo, o milho e o arroz (SGARBIERI, 1996). O arroz é uma das maiores produções de grãos no mundo, sendo o Brasil o principal produtor entre os países ocidentais (BARATA, 2005).

$\mathrm{O}$ arroz pode ser utilizado para consumo humano sob diversas formas: arroz polido, parboilizado e integral; óleo e farinha comercial de arroz, entre outros. Grande parte do arroz polido é consumida diretamente após cozido, mas uma parte significativamente crescente tem sido usada industrialmente na produção de farinha de arroz que é, posteriormente, utilizada como aditivo em gel, pudins, sorvetes e outros produtos similares devido às suas propriedades nutricionais, sua hipoalergenicidade, por possuir sabor agradável e por não interferir na cor do produto final (BRASIL, 1978; CHRASTIL, 1992; JU; HETTIARACHCHY; RATH, 2001; SHIH; DAIGLE, 2000).

O conteúdo de proteína na farinha comercial de arroz é relativamente baixo (7 a 9\%). Entretanto, dentre os componentes do arroz, as proteínas têm sido consideradas de grande valor, pois são hipoalergênicas, particularmente saudáveis para o consumo humano e altamente nutritivas em relação aos outros cereais. $\mathrm{O}$ conteúdo de lisina é de 3 a 4\%, aproximadamente 50\% maior que o do trigo, por exemplo (JU; HETTIARACHCHY; RATH, 2001; SHIH; DAIGLE, 2000).

As proteínas são classificadas na base de solubilidade em albuminas (solúveis em água), globulinas (solúveis em soluções salinas), prolaminas (solúveis em álcool) e glutelinas (solúveis em álcalis). A fração das glutelinas corresponde à maior parte das proteínas do arroz, o que representa cerca de 80\% (HAMADA, 1997; JU; HETTIARACHCHY; RATH, 2001; JULIANO, 2006; SGARBIERI, 1996).

A produção de isolados protéicos de arroz consiste, geralmente, em uma extração alcalina de seus subprodutos, como a farinha comercial de arroz, seguida pela precipitação das proteínas pelo ajuste do $\mathrm{pH}$ no ponto isoelétrico. Têm sido reportados na literatura métodos descrevendo o uso de soluções alcalinas para extração de proteínas do arroz (BIZZOTTO et al., 2006;

Recebido para publicação em 19/3/2007

Aceito para publicação em 10/4/2008 (002405)

${ }^{1}$ Departamento de Alimentos, Faculdade de Farmácia, Universidade Federal de Minas Gerais - UFMG, Av. Antônio Carlos, 6627, sala 3070, bloco 03, CEP 31270-901, Belo Horizonte - MG, Brasil, E-mail: malice@farmacia.ufmg.br

${ }^{*}$ A quem a correspondência deve ser enviada 
BIZZOTTO et al., 2006b; CONNOR; SAUNDERS; KOHLER, 1976; LINDSAY; SAUNDERS; KOHLER, 1977).

Entretanto, condições alcalinas usadas nesse processo de extração podem causar reações secundárias indesejáveis e potencial toxicidade, tal como a formação de lisinoalanina, acarretando perda do valor nutritivo das proteínas. Outras conseqüências são a desnaturação protéica e a ocorrência de reação de Maillard, que causam o escurecimento dos produtos e maior extração de componentes não protéicos que co-precipitam com a proteína e diminuem a qualidade do isolado protéico (WANG et al., 1999).

Em vários estudos têm-se procurado isolar as proteínas do arroz, a partir de seus produtos como a farinha e o farelo, pela remoção enzimática de conteúdos não protéicos. Diversas enzimas têm sido utilizadas, entre estas, encontram-se a pancreatina, as proteases alcalinas, fúngicas ou bacterianas, em conjunto ou não com a ação de amilases e carboidrases (AGBOOLA; NG; MILLS, 2005; ANSHARULLAH; CHESTERMAN, 1997; EUBER; PUSKI; HARTMAN JR., 1991; FISCHER et al., 2001; SHAW; SHEU, 1992; SHIH et al., 1999; SHIH; DAIGLE, 1997; SHIH; DAIGLE, 2000; TANG; HETTIARACHCHY; SHELLHAMMER, 2002; WANG et al., 1999).

Em outros casos, métodos enzimáticos foram desenvolvidos com o principal objetivo de isolar apenas o amido do arroz, utilizando proteases alcalinas e/ou neutras; no entanto, os baixos conteúdos de proteína obtidos no amido indicam que é possível obter subprodutos ricos em proteína (LUMDUBWONG; SEIB, 2000; WANG; WANG, 2001; WANG; WANG, 2004a).

Alguns autores têm utilizado tratamentos físicos (ultrasom, agitação à alta velocidade, alta pressão, etc) na extração de proteínas do arroz e de seus produtos. Dependendo dos fatores e do tipo de matéria-prima empregados, os resultados reportados na literatura associam uma correlação positiva do emprego de processos físicos com o rendimento de extração protéica (TANG; HETTIARACHCHY; SHELLHAMMER, 2002; WANG; WANG, 2001; WANG; WANG, 2004a; WANG; WANG, 2004b).

Levando-se em conta a posição relevante que ocupa o arroz na dieta do brasileiro, e a qualidade de suas proteínas, seria de grande interesse utilizá-lo como matéria-prima para a produção de alimentos para fins dietéticos especiais, com diversas aplicações relevantes para as áreas de nutrição e saúde. O primeiro passo neste sentido consiste na extração das proteínas, que foi estudada no presente trabalho, empregando-se o método enzimático e verificando-se o efeito de diversos parâmetros neste processo, com o intuito de obter elevado rendimento de extração.

\section{Material e métodos}

\subsection{Material}

A farinha comercial de arroz foi fornecida pela FERLA - L. FERENCZI Indústria e Comércio Ltda. (São Paulo, SP, Brasil). Foi utilizada uma protease alcalina, Protemax 580 L (EC 3.4.21.14, uma serino-endopeptidase de origem bacteriana - cepa do
Bacillus licheniformis, atividade 580 KDU.g ${ }^{-1}$, estável em pH entre 7 e 10 , com pH ótimo em 9,5, temperatura ótima de $60^{\circ} \mathrm{C}$ e temperatura de inativação acima de $85^{\circ} \mathrm{C}$ por 10 minutos) e outra protease neutra, Protemax ${ }^{\oplus}$ N200 (EC 3.4.21.62, uma serino-endopeptidase de origem bacteriana - cepa do Bacillus subtilis, atividade $200 \mathrm{NU} \cdot \mathrm{g}^{-1}$, estável em pH entre 4,7 e 7,5, com $\mathrm{pH}$ ótimo entre 7 e 7,5 , temperatura ótima de $55^{\circ} \mathrm{C}$ e temperatura de inativação acima de $80^{\circ} \mathrm{C}$ por 20 minutos), que foram cedidas pela Prozyn (São Paulo, SP, Brasil). Os demais reagentes foram de grau analítico.

\subsection{Métodos}

\section{Determinação da composição centesimal e do} valor calórico da matéria-prima

A farinha comercial de arroz foi acondicionada em potes de vidro, hermeticamente fechados e mantidos sob refrigeração, até o momento de uso.

Todas as análises da composição química da matéria-prima foram realizadas em triplicata segundo as metodologias descritas pela Association of Official Analytical Chemists (1995). $\mathrm{O}$ teor de umidade foi determinado por dessecação em estufa ventilada (Quimis Q-314M242 série 020, Diadema, SP) a $105^{\circ} \mathrm{C}$ até peso constante; o teor de proteína, pelo método de micro-Kjeldahl; os lipídios, por extração com éter etílico, pelo método de Soxhlet modificado (Quimis Q-308G26, série 018, Diadema, SP); os minerais, por incineração em mufla a $550{ }^{\circ} \mathrm{C}$; e os carboidratos, por diferença.

O fator utilizado na conversão do teor de nitrogênio em proteína foi de 5,95 , baseado no teor de nitrogênio da fração glutelina do arroz (16,8 g N.100 g-1 de proteína) (SGARBIERI, 1996). A energia está expressa em quilocalorias (kcal) e os valores foram calculados empregando-se os fatores de conversão de 4 kcal.g-1 para proteína e carboidratos e de $9 \mathrm{kcal}^{-1} \mathrm{~g}^{-1}$ para lipídios (USDA, 2006).

\section{Extração enzimática das proteínas da} farinha comercial de arroz

Empregou-se um método de extração enzimática das proteínas da farinha comercial de arroz, utilizando o procedimento descrito por Wang e Wang (2001) e modificado por Capobiango et al. (2006). Algumas adaptações adicionais foram realizadas visando aumentar o Rendimento de Extração Protéica (REP), tais como $\mathrm{pH}$, tempo e temperatura empregados.

No preparo dos extratos protéicos de farinha de arroz (EPFA), os seguintes parâmetros foram avaliados: tipo de enzima; $\mathrm{pH}$; temperatura; tratamento físico; concentração da matéria-prima; e relação Enzima:Substrato (E:S).

\section{Avaliação do efeito do tipo de enzima}

Foram testadas duas enzimas: uma protease alcalina (Protemax ${ }^{\circ} 580 \mathrm{~L}-$ Bacillus licheniformis) e uma protease neutra (Protemax ${ }^{\oplus}$ N 200 - Bacillus subtilis), que foram anteriormente utilizadas por Capobiango et al. (2006) e por Wang e Wang 
(2001) na extração enzimática das proteínas do fubá de milho e para isolar o amido de arroz, respectivamente.

A farinha comercial de arroz foi suspensa em água destilada na proporção de 1:5 (p/v) e benzoato de sódio foi adicionado em quantidade necessária para uma concentração final de $0,1 \%(\mathrm{p} / \mathrm{v})$. A suspensão foi agitada no ultra-turrax (IKA Labortechnix, T25 basic, Wilmington, EUA) a $16.000 \mathrm{rpm}$ por 5 minutos, e as enzimas adicionadas na relação E:S de 10:100, em suas condições ótimas de $\mathrm{pH}$ e temperatura, ou seja, a protease alcalina em pH 9,5 a $60^{\circ} \mathrm{C}$ e a protease neutra em $\mathrm{pH} 7,5 \mathrm{a}$ $55^{\circ} \mathrm{C}$. $\mathrm{O}$ ajuste do $\mathrm{pH}$ foi realizado com solução de $\mathrm{NaOH}$ a 3 mol.L $\mathrm{L}^{-1}$ e a temperatura controlada em banho de vaselina líquida, sobre agitador magnético.

A extração enzimática foi realizada por 5 horas com agitação constante. Após este tempo, a suspensão foi resfriada até $25^{\circ} \mathrm{C}$ e centrifugada por 15 minutos a $1.700 \times$ g. O EPFA foi recolhido, separadamente, em um recipiente, e o resíduo foi então lavado duas vezes com água destilada na proporção $1: 2(\mathrm{p} / \mathrm{v})$, repetindo-se a etapa de centrifugação entre as lavagens e recolhendo sempre o EPFA no mesmo recipiente. O resíduo foi pesado e submetido à determinação do teor de proteína.

Avaliação do efeito da temperatura

Para avaliar esse parâmetro, três valores foram testados: 40, 50 e $60{ }^{\circ} \mathrm{C}$, usando a enzima e as condições que proporcionaram o maior REP no item anterior. Os valores de temperatura empregados foram baseados em estudo realizado por Euber et al. (1991), que empregaram a faixa de 35 a $60{ }^{\circ} \mathrm{C}$ para verificar o efeito da temperatura na solubilização das proteínas por diversas proteases.

\section{Avaliação do efeito do pH}

Utilizando a condição em que se obteve o maior REP no item Avaliação do efeito da temperatura, três valores de $\mathrm{pH}$ foram testados: 9,5, 10,5 e 11,0, dentro da faixa usada por Bizzotto et al. (2006b). Os valores de $\mathrm{pH}$ dos extratos obtidos foram medidos após o término da extração.

\section{Avaliação do efeito do tratamento físico}

Baseado em estudo realizado por Tang et al. (2002), os tratamentos físicos avaliados foram ultra-turrax a $16.000 \mathrm{rpm}$ e ultra-som a 120 W. Nos dois casos, variou-se o tempo de ação em 5, 10 e 15 minutos. Uma amostra controle, sem tratamento físico, foi também preparada. Os outros parâmetros utilizados nessa etapa foram aqueles que proporcionaram um maior REP no item anteriormente descrito (Avaliação do efeito do pH).

Avaliação do efeito da concentração da matéria-prima e da relação enzima:substrato

Neste caso, três valores foram testados para a relação matéria-prima:água (MP: $\mathrm{H}_{2} \mathrm{O}$ ), de acordo com aqueles utilizados em outros estudos por diversos autores. Os valores empregados foram de 1:3 p/v (WANG; WANG, 2001), 1:5 p/v (CAPOBIANGO et al., 2006) e 1:10 p/v (SHAW; SHEU, 1992) para a melhor condição encontrada no item Avaliação do efeito do tratamento físico. O efeito da relação E:S foi investigado no valor utilizado por Capobiango et al. (2006), igual a 10:100 e em um inferior, E:S de 5:100, para todas as três concentrações da matéria-prima.

Determinação do rendimento da extração protéica

Para cada parâmetro estudado, o Rendimento da Extração Protéica (REP) foi determinado, conforme a Equação 1:

$\mathrm{REP}=\frac{[(\mathrm{A} \times \mathrm{B})-(\mathrm{C} \times \mathrm{D})]}{(\mathrm{A} \times \mathrm{B})} \times 100$

sendo:
$\mathrm{A}=$ teor de proteína na farinha de arroz;
B = quantidade de farinha de arroz utilizada na extração;
$\mathrm{C}=$ peso de resíduo obtido na extração; e
$\mathrm{D}=$ teor de proteína no resíduo.

\subsection{Análise estatística}

Cada experimento foi realizado em três repetições, no mesmo dia, e as análises foram realizadas em triplicata. Utilizou-se a Análise de Variância (ANOVA fator único) e o Teste de Duncan a 5\% de probabilidade, para comparar o REP em relação ao efeito dos parâmetros empregados na extração enzimática das proteínas de farinha de arroz (PIMENTEL-GOMES, 2000).

\section{Resultados e discussão}

\subsection{Composição química e valor calórico da matéria-prima}

Os dados referentes à composição química da farinha comercial de arroz estão apresentados na Tabela 1. De uma forma geral, a composição centesimal da farinha comercial de arroz assemelha-se aos resultados das análises do fornecedor da matéria-prima, bem como aos dados citados na literatura. Algumas diferenças encontradas podem ser explicadas pelo fato de que os fatores ambientais durante o cultivo afetam a composição do grão de arroz (JULIANO, 2006). No caso das análises do fornecedor da matéria-prima, acredita-se que os métodos empregados na determinação destes componentes podem ter influenciado nos resultados obtidos, embora não tenham sido mencionados na literatura consultada.

Observa-se que o valor encontrado para carboidratos é semelhante aos valores citados em bases de dados, como as do USDA (2006) e da USP (2006), e aos relatados por Hagenimana et al. (2006), Murthy et al. (2007) e Ilo et al. (1999). Quanto ao teor de lipídios, este ficou próximo àqueles reportados por Murthy et al. (2007) e Ilo et al. (1999), enquanto o de cinzas se aproxima de alguns, como os reportados por Ilo et al. (1999) e Hagenimana et al. (2006), sendo inferior aos demais.

O teor de proteína observado no presente trabalho está próximo aos valores de Hagenimana et al. (2006), USDA (2006) e USP (2006), sendo inferior aos de Murthy et al. (2007) e Ilo et al. (1999). Pode-se justificar tal diferença devido aos fatores 
Tabela 1. Composição química da farinha comercial de arroz.

\begin{tabular}{|c|c|c|c|c|c|c|}
\hline & $\begin{array}{l}\text { Umidade } \\
\left(\text { g. } 100 \mathrm{~g}^{-1}\right)\end{array}$ & $\begin{array}{l}\text { Proteína } \\
\left(\text { g.100 g }{ }^{-1}\right)\end{array}$ & $\begin{array}{l}\text { Lipídios } \\
\left.\text { (g.100 g }{ }^{-1}\right)\end{array}$ & $\begin{array}{c}\text { Cinzas } \\
\left(\text { g. } 100 \mathrm{~g}^{-1}\right)\end{array}$ & $\begin{array}{c}\text { Carboidratos } \\
\left(\mathrm{g} .100 \mathrm{~g}^{-1}\right)\end{array}$ & $\begin{array}{c}\text { Calorias } \\
\left(\mathrm{kcal} .100 \mathrm{~g}^{-1}\right)\end{array}$ \\
\hline Valores obtidos $^{1}$ & 9,27 & $6,61^{3}$ & 0,82 & 0,42 & 82,88 & 365,3 \\
\hline Ferla $^{2}$ & 9,60 & $6,96^{4}$ & 0,90 & 0,60 & 81,94 & 363,7 \\
\hline Hagenimana et al. (2006) & 12,40 & $6,71^{4}$ & 0,41 & 0,39 & 80,10 & - \\
\hline Murthy et al. (2007) & 11,00 & $7,50^{4}$ & 0,80 & 0,70 & 80,00 & - \\
\hline Ilo et al. (1999) & - & $8,13^{5}$ & 0,77 & 0,47 & - & - \\
\hline USDA (2006) & 11,89 & $6,05^{6}$ & 1,42 & 0,61 & 80,13 & 366 \\
\hline USP (2006) & 11,60 & $6,90^{4}$ & 1,10 & 0,70 & 79,70 & 354 \\
\hline
\end{tabular}

Resultados encontrados no presente trabalho; ${ }^{2}$ valores fornecidos pelo fornecedor da matéria-prima; ${ }^{3}$ fator de conversão do teor de nitrogênio em proteína igual a 5,$95 ;{ }^{4}$ fator de conversão do teor de nitrogênio em proteína não especificado; ${ }^{5}$ fator de conversão do teor de nitrogênio em proteína igual a 6,25 ; e ${ }^{6}$ fator de conversão do teor de nitrogênio em proteína igual a 5,85 .

de conversão do teor de nitrogênio em proteína, que não foram os mesmos usados no presente trabalho, bem como às condições de cultivo do arroz que contribuem para aumentar o teor de proteína, como solo, clima e possível aplicação de grandes quantidades de fertilizantes nitrogenados (JULIANO, 2006).

\subsection{Efeito dos parâmetros estudados na extração enzimática das proteínas}

\section{Efeito do tipo de enzima}

Para avaliar o efeito do tipo de enzima no REP, duas proteases foram testadas sob condições ótimas de temperatura e $\mathrm{pH}$. O método que usou a protease alcalina obteve um REP de $50,7 \%$, significativamente superior àquele utilizando a protease neutra $(28,6 \%)$.

Não foram encontrados na literatura trabalhos que comparassem o efeito do tipo de protease na extração direta das proteínas do arroz. No entanto, Euber et al. (1991), visando a obtenção de concentrado protéico solúvel de arroz, após tratamento prévio com uma alfa-amilase, utilizaram diversos tipos de proteases para solubilizar/extrair a proteína do resíduo obtido. Estes autores verificaram que, como obtido no presente trabalho, a ação de uma protease bacteriana alcalina foi mais eficiente que uma protease bacteriana neutra, obtendo valores de rendimento protéico iguais a 47,0 e $33,5 \%$, respectivamente.

A maior eficiência da ação de uma protease alcalina em relação à neutra na extração de proteínas do arroz deve estar relacionada ao meio alcalino utilizado, potencializando dessa forma a extração das glutelinas, maior fração protéica da matéria-prima, e que é relativamente solúvel em álcalis.

\section{Efeito da temperatura}

O método em que foi usada a protease alcalina foi escolhido para ser utilizado nesta etapa, uma vez que proporcionou um maior REP. Foram, então, fixados os demais parâmetros de extração (relação E:S de 10:100, pH 9,5, concentração de matéria-prima de $1: 5 \mathrm{p} / \mathrm{v}$, tratamento físico com ultra-turrax a $16.000 \mathrm{rpm} / 5$ minutos), variando apenas a temperatura utilizada.
Pode-se notar na Figura 1, que a temperatura de $50{ }^{\circ} \mathrm{C}$ apresentou diferença significativa das demais $\left(49,4 \%\right.$ para $40{ }^{\circ} \mathrm{C}$ e $50,7 \%$ para $60^{\circ} \mathrm{C}$ ), sendo a mais vantajosa, pois levou ao maior $\operatorname{REP}(53,5 \%)$. No caso de se usar a temperatura de $40^{\circ} \mathrm{C}$, o resultado inferior a $50^{\circ} \mathrm{C}$ poderia ser explicado pelo fato de que o aquecimento foi insuficiente para a extração protéica. Enquanto que o emprego da temperatura de $60^{\circ} \mathrm{C}$, apesar de corresponder ao valor ótimo para esta enzima, levou a um resultado inferior a $50{ }^{\circ} \mathrm{C}$, provavelmente por estar próximo da temperatura de gelatinização do amido do arroz, que está na faixa de 61 a $77^{\circ} \mathrm{C}$ (BOBBIO; BOBBIO, 1992). Neste processo, parte das proteínas ligadas às moléculas de amido poderia estar inacessível à ação da enzima (CHRASTIL, 1992). Além disso, acima de $50{ }^{\circ} \mathrm{C}$ as proteínas começam a sofrer desnaturação e a solubilidade tende a diminuir (SGARBIERI, 1996).

Da mesma maneira, Ansharullah e Chesterman (1997), utilizando uma combinação de duas carboidrases, ao invés de proteases, na obtenção de concentrado protéico do arroz, observaram que a extração foi maior quando o processo foi conduzido à temperatura de $50^{\circ} \mathrm{C}$, em relação ao usado a $40^{\circ} \mathrm{C}$, tendo obtido REP de 54,42 e 51,17\% em termos de nitrogênio extraído, respectivamente.

Capobiango et al. (2006) também observaram valor inferior do REP à temperatura de $60^{\circ} \mathrm{C}(81,2 \%)$ em relação à de $55^{\circ} \mathrm{C}$ $(83,8 \%)$. Segundo esses autores, o efeito associando o emprego de temperatura inferior com um maior valor de rendimento é desejável, uma vez que proporciona a redução de custos do processo.

Resultados semelhantes foram observados por outros autores. Assim, Euber et al. (1991) estudando o efeito da temperatura no REP, utilizaram a pancreatina para solubilizar as proteínas do resíduo de arroz obtido após a extração do amido pela ação de alfa-amilase. Os resultados mostraram que quanto maior a temperatura utilizada, maior foi o REP $\left(72,0 \%\right.$ para $35{ }^{\circ} \mathrm{C}$ e $75,8 \%$ para $45^{\circ} \mathrm{C}$ ). Entretanto, ao se utilizar a temperatura de $60{ }^{\circ} \mathrm{C}$ observou-se uma queda no $\operatorname{REP}\left(75,5 \%\right.$ para $50^{\circ} \mathrm{C}$ e $71,4 \%$ para $\left.60^{\circ} \mathrm{C}\right)$.

\section{Efeito do $\mathrm{pH}$}

Para avaliar o efeito do $\mathrm{pH}$, a temperatura de $50^{\circ} \mathrm{C}$ foi escolhida por ter promovido um maior REP. Os outros parâmetros 
foram também fixados (protease alcalina na relação E:S de 10:100, concentração de matéria-prima de $1: 5 \mathrm{p} / \mathrm{v}$, tratamento físico com ultra-turrax a $16.000 \mathrm{rpm} / 5$ minutos).

$\mathrm{Na}$ Figura 2 pode ser notado que o $\mathrm{pH} 11,0$ foi o que deu origem ao maior REP (63,6\%), seguido do $\mathrm{pH} 10,5$ (57,6\%), e por último o pH 9,5 (53,5\%). Embora o pH ótimo de atuação da enzima seja igual a 9,5 (segundo informação do fornecedor). O emprego de um valor mais elevado pode ter provocado uma maior solubilização da fração glutelina, que corresponde à maior parte das proteínas do arroz, e que são relativamente solúveis em álcali, o que explica o valor mais elevado de REP. De acordo com Ju et al. (2001), estudos realizados por outros autores demonstraram que $98 \%$ de extração da fração glutelina foi obtida em pH 11,8 e que, em pH abaixo de 10,0, a solubilidade dessa fração foi reduzida drasticamente.

Bizzotto et al. (2006b), buscando a otimização do método de extração alcalina para obtenção do extrato protéico bruto de arroz, relataram, igualmente, que o emprego de valor mais elevado de $\mathrm{pH}$ foi benéfico para o rendimento de extração, sendo que no $\mathrm{pH} 12,0$ extraiu-se $65 \%$ das proteínas e no $\mathrm{pH} 10$ a extração atingiu apenas 59\%.

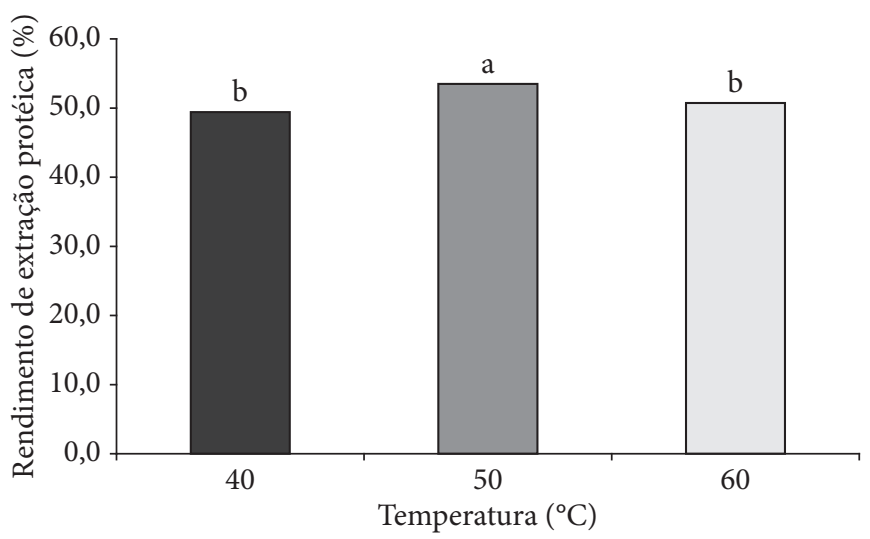

Figura 1. Efeito da temperatura no rendimento de extração protéica.

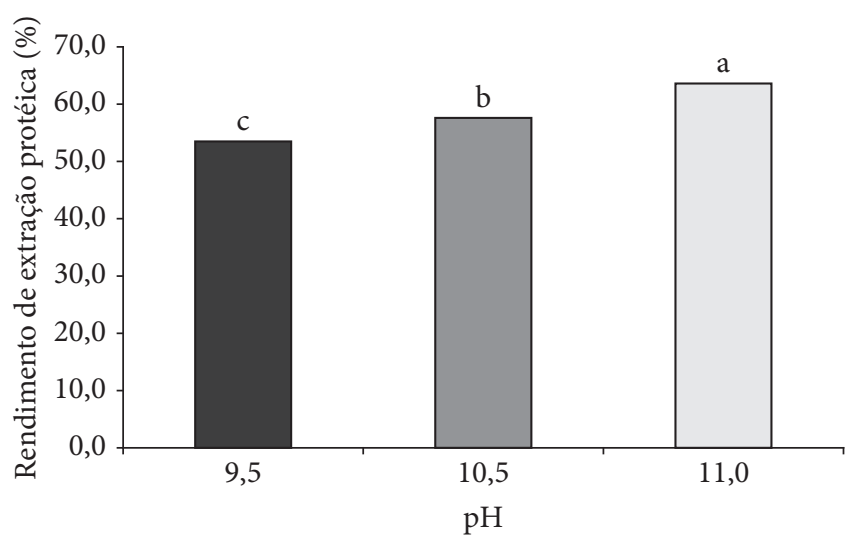

Figura 2. Efeito do pH no rendimento da extração protéica.
Observou-se, ainda, no presente estudo, que durante a extração enzimática ocorreu uma queda no valor do $\mathrm{pH}$. Isto se deve à hidrólise enzimática de proteínas, na qual ocorre a quebra das ligações peptídicas e, conseqüentemente, a liberação de grupamentos terminais dos peptídeos. Em soluções aquosas, estes grupos se encontram na forma ionizável $\left(\mathrm{COO}^{-}+\mathrm{H}^{+}\right)$, e os prótons livres neutralizam a alcalinidade do meio (GUADIX, 2000; LEHNINGER; NELSON; COX, 1995).

No caso dos valores de $\mathrm{pH}$ 10,5 e 9,5, o pH final ficou bem próximo à neutralidade, tendo atingido os valores de 7,4+0,1 e $6,7+0,2$, respectivamente. Para o $\mathrm{pH}$ de 11,0 a queda foi menor, tendo o $\mathrm{pH}$ final ficado em 8,2+0,2. Assim, embora em pH 11,0 tenha se obtido um maior REP, esta condição apresenta como desvantagem o fato de ser necessário proceder a neutralização, o que levaria à formação de sal no produto final (FURLAN; OETTERER, 2002).

Esse fenômeno do abaixamento do $\mathrm{pH}$ foi também constado por Euber et al. (1991) ao utilizar uma pancreatina, em $\mathrm{pH} 8,0$, para solubilizar as proteínas do resíduo de arroz obtido após a extração do amido pela ação de alfa-amilase. Os autores relataram que ao final do processo o $\mathrm{pH}$ ficou entre 6,9 e 7,5. O mesmo foi relatado por Capobiango et al. (2006) ao observarem que, na extração enzimática das proteínas do fubá de milho, o $\mathrm{pH}$ final, inicialmente ajustado no valor de 9,5, situava-se em torno de 7,0 .

\section{Efeito do tratamento físico}

A avaliação deste parâmetro foi realizada fixando-se o pH em 10,5, uma vez que neste valor obteve-se a melhor condição de extração protéica. Desta forma, o efeito do tratamento físico no REP foi estudado fixando-se também os demais parâmetros (protease alcalina na relação E:S de 10:100, concentração de matéria-prima de $1: 5 \mathrm{p} / \mathrm{v}$, temperatura de $50^{\circ} \mathrm{C}$ ). O tratamento físico foi estudado utilizando ultra-turrax a $16.000 \mathrm{rpm}$ e ultrasom a $120 \mathrm{~W}$, ambos por 5, 10 e 15 minutos, sendo que em uma amostra não foi aplicado qualquer tipo de tratamento físico.

\section{Efeito do tempo de tratamento}

Como pode ser visto na Tabela 2, o tempo de tratamento não influenciou o REP. Assim, ao se comparar os extratos para os quais foram utilizados diferentes tempos de ação do ultraturrax, observa-se que não houve diferença significativa entre os

Tabela 2. Efeito do tratamento físico no rendimento de extração protéica.

\begin{tabular}{ccc}
\hline Tipo de tratamento & Tempo (minuto) & $\begin{array}{c}\text { Rendimento de } \\
\text { extração protéica (\%) }\end{array}$ \\
\hline Sem tratamento & - & $60,3^{\mathrm{a}}$ \\
Ultra-turrax & 5 & $57,6^{\mathrm{b}}$ \\
& 10 & $57,2^{\mathrm{b}}$ \\
Ultra-som & 15 & $58,1^{\mathrm{b}}$ \\
& 5 & $55,1^{\mathrm{c}}$ \\
& 10 & $54,9^{\mathrm{c}}$ \\
\hline
\end{tabular}

Os resultados representam a média das repetições. Médias indicadas por letras iguais não diferem entre si a $5 \%$ de probabilidade pelo teste de Duncan. 
valores de REP, cujo valor médio foi de 57,6\%. O mesmo ocorreu quando comparados os extratos para os quais se empregou o ultra-som com tempos diferentes de ação, tendo obtido o valor médio de 55,0\%.

Resultados semelhantes (46,9\% de rendimento) foram obtidos por Wang e Wang (2004b), ao estudarem o efeito do tempo de ação do ultra-som para aumentar o rendimento de extração do amido em farinha de arroz comercial, utilizando uma potência de $187 \mathrm{~W}$ e tempos de 30 e 60 minutos. Os autores observaram nesse experimento que o tempo de ação não alterou o rendimento.

\section{Efeito do tipo de tratamento}

Para avaliar este parâmetro, devem-se comparar os extratos em que se utilizaram o ultra-turrax e o ultra-som no mesmo tempo de tratamento. Observa-se que, em todos os casos, os resultados obtidos com o ultra-turrax foram ligeiramente superiores que os do ultra-som (Tabela 2).

Tang et al. (2002) também investigaram o efeito do tipo de tratamento físico sobre o rendimento de extração protéica do farelo desengordurado de arroz. Neste caso, as diferenças observadas foram mais acentuadas do que as do presente estudo, uma vez que o REP para o ultra-som foi de $26,3 \%$, enquanto que para o liquidificador de alta velocidade foi de $52,8 \%$.

\section{Comparação entre extração com e sem tratamento físico}

Comparando entre si os melhores resultados de REP, obtidos com tratamento físico (ultra-turrax) e sem tratamento, mantendo-se as demais condições constantes, observa-se na Tabela 2 que o emprego do tratamento físico não foi vantajoso, uma vez que a amostra sem tratamento apresentou resultado significativamente superior $(60,3 \%)$ ao da amostra com tratamento $(57,6 \%$, em média).

Resultados semelhantes foram relatados por Tang et al. (2002), ao tratarem o farelo desengordurado de arroz com ultrasom. De acordo com os autores, este tratamento não influenciou significativamente no REP. Por outro lado, os mesmos autores também investigaram o emprego de um liquidificador de alta velocidade com o objetivo de aumentar a extração das proteínas, e verificaram que a extração protéica sem tratamento extraiu $48,4 \%$ das proteínas do farelo de arroz, enquanto que com a ação do tratamento físico, o rendimento aumentou para 52,8\%.

\section{Efeito da relação enzima:substrato e da concentração da matéria-prima}

Para avaliar estes parâmetros, a extração protéica foi realizada sem tratamento físico, uma vez que este foi mais vantajoso para o REP. Os outros parâmetros empregados foram fixados (protease alcalina, $\mathrm{pH}$ 10,5 e temperatura de $50^{\circ} \mathrm{C}$ ) variando-se a relação E:S e a concentração de matéria-prima.

A relação E:S de 5:100 e 10:100 foi avaliada em três diferentes concentrações de matéria-prima (1:3, 1:5 e 1:10 p/v). Verifica-se, através da Tabela 3, que para todos os casos, o emprego de maior relação E:S foi mais vantajoso, pois levou ao
Tabela 3. Efeito da concentração da matéria-prima e da relação enzima: substrato no rendimento de extração protéica.

\begin{tabular}{ccc}
\hline $\begin{array}{c}\text { Concentração de } \\
\text { matéria-prima } \\
(\mathrm{p} / \mathrm{v})\end{array}$ & Relação E:S & $\begin{array}{c}\text { Rendimento de } \\
\text { extração } \\
\text { protéica }(\%)\end{array}$ \\
\hline $1: 3$ & $5: 100$ & $43,7^{\mathrm{f}}$ \\
& $10: 100$ & $47,9^{\mathrm{e}}$ \\
$1: 5$ & $5: 100$ & $53,6^{\mathrm{d}}$ \\
& $10: 100$ & $60,3^{\mathrm{b}}$ \\
$1: 10$ & $5: 100$ & $57,8^{\mathrm{c}}$ \\
& $10: 100$ & $63,4^{\mathrm{a}}$ \\
\hline
\end{tabular}

Relação E:S = relação enzima:substrato. Os resultados representam a média das repetições. Médias indicadas por letras iguais não diferem entre si a 5\% de probabilidade pelo teste de Duncan.

maior REP, tendo os valores variado de 43,7 para $47,9 \%$, de 53,6 para $60,3 \%$ e de 57,8 para $63,4 \%$ nas concentrações de matériaprima de 1:3, 1:5 e 1:10 p/v, respectivamente.

Ansharullah e Chesterman (1997) relataram o mesmo efeito benéfico relacionado ao aumento da E:S ao utilizar apenas uma das carboidrases testadas na obtenção do concentrado protéico de arroz. Assim, os autores utilizaram concentrações que variaram de 22,5 a 112,5 (unidades FBG), extraindo de 16,99 a $47,64 \%$ de nitrogênio.

Euber et al. (1991) obtiveram resultados semelhantes ao estudar o efeito da concentração da enzima no REP. Quando os autores dobraram a concentração de pancreatina (de 1 para $2 \%$ ), houve um aumento de 71,2 para $75,5 \%$ no REP.

Para avaliar o efeito da concentração de matéria-prima no REP, devem ser observados os extratos em que se utilizou a relação E:S de 10:100, visto que esta proporcionou um maior REP quando comparada com a relação E:S de 5:100.

Observa-se, na Tabela 3, que quanto menor a concentração da matéria-prima, maior foi o REP, uma vez que os valores obtidos foram de 47,9, 60,3 e 63,4\% nas concentrações de matéria-prima de 1:3, 1:5 e 1:10 p/v, respectivamente. Este resultado poderia ser, pelo menos em parte, explicado pela maior mobilidade da enzima em um meio mais diluído, o que facilitaria a sua ação. Ressalta-se, ainda, que não foram encontrados na literatura estudos abordando o efeito deste parâmetro sobre o REP em produtos à base de arroz.

\subsection{Eficiência da extração enzimática das proteínas}

Os valores de REP obtidos no presente trabalho variaram de 28,6 a 63,6\%, sendo que, na grande maioria das condições testadas, obteve-se um REP acima de 50\%. O valor máximo para REP atingido ficou em torno de $63,5 \%$, para os extratos em que se empregou a protease alcalina a $50{ }^{\circ} \mathrm{C}$, no $\mathrm{pH} 10,5$ ou 11,0, sem ou com ultra-turrax a $16.000 \mathrm{rpm} / 5$ minutos, nas relações E:S de 10:100 e concentrações de matéria-prima de 1:10 ou 1:5 (p/v), respectivamente. Como pode ser visto nos relatos abaixo, estes resultados estão dentro da faixa dos valores reportados para a maioria dos trabalhos encontrados na literatura, para o rendimento da extração enzimática das proteínas de arroz e de seus subprodutos (ANSHARULLAH; 
CHESTERMAN, 1997; EUBER; PUSKI; HARTMAN JR., 1991; TANG; HETTIARACHCHY; SHELLHAMMER, 2002).

Euber et al. (1991), ao desenvolverem um método enzimático para produção de concentrado protéico solúvel de arroz utilizaram, primeiramente, uma alfa-amilase para solubilizar e isolar o amido para, em seguida, extrair enzimaticamente as proteínas usando diferentes tipos de proteases. Estes autores obtiveram rendimentos de extração que variaram de 17 a 75,5\%, dependendo do tipo de protease empregada ( $17 \%$ para papaína, $33,5 \%$ para protease bacteriana neutra, $47 \%$ para protease bacteriana alcalina e $75 \%$ para pancreatina). Embora o uso da pancreatina tenha proporcionado um rendimento mais elevado do que o do presente trabalho, o tratamento prévio com amilase elevaria os custos do processo, especialmente quando adaptado para larga escala.

Tang et al. (2002) obtiveram um rendimento de extração protéica em torno de $53 \%$, ao utilizarem uma protease de Aspergillus sp. (Amano P), seguida de tratamento físico (liquidificador de alta velocidade) no farelo de arroz desengordurado. Ansharullah e Chesterman (1997), aplicando carboidrases isoladas ou combinadas na extração de proteínas do farelo de arroz, também obtiveram rendimentos que variaram de 25,94 a $57,89 \%$ em termos de nitrogênio extraído, dentro da faixa da maioria dos valores aqui obtidos. Os resultados reportados por esses autores reforçam que os rendimentos de extração protéica em produtos de arroz são relativamente inferiores quando comparados a outros cereais.

Em pesquisa visando à utilização do fubá de milho como matéria-prima para a produção de suplementos nutricionais diversos, Capobiango et al. (2006) extraíram enzimaticamente as proteínas usando a mesma protease alcalina empregada neste trabalho. Os resultados reportados pelos autores foram superiores aos aqui encontrados, tendo o rendimento de extração variado de 71,5 a $86,8 \%$. O fato de que os valores encontrados para o fubá de milho sejam superiores aos do arroz está associado às diversas diferenças entre as matérias-primas, ou seja, da matriz alimentar utilizada nos dois trabalhos.

A extração incompleta das proteínas do arroz em relação às proteínas do fubá de milho, provavelmente se deve à interferência da matriz (FISCHER et al., 2001). No caso das proteínas do arroz, a presença de ligações dissulfídicas e interações não covalentes entre as cadeias polipeptídicas e/ou cadeias polipeptídicas e outros constituintes, como lipídios e carboidratos, contribui para a sua baixa solubilidade, o que explicaria a dificuldade encontrada para a sua extração (WANG; FERNANDES; CABRAL, 2000). Com relação à principal fração protéica do arroz, as glutelinas, pode-se ainda acrescentar que a exata razão para a sua insolubilidade não é bem conhecida. Entretanto, muitas investigações sugerem que fatores, tais como a extensa agregação protéica, a presença de pontes de dissulfeto e a glicosilação podem ser responsáveis pela sua insolubilidade (HAMADA, 1997).

Quanto ao teor de proteínas do resíduo obtido na extração protéica, este variou de 2,87 a 5,59\%. Nos demais relatos encontrados na literatura, os valores obtidos para o teor de proteínas do resíduo foram inferiores aos do presente trabalho. Assim,
Lumdubwong e Seib (2000) e Agboola et al. (2005), trabalhando com arroz em grão, e Wang e Wang (2004a) com farinha de arroz, obtiveram 0,50, 0,15 e 0,55\% de proteína em seus resíduos, respectivamente. Capobiango et al. (2006) encontraram valores entre 1,2 e 2,3\% nos resíduos obtidos após a extração enzimática das proteínas de fubá de milho. As diferenças encontradas estão relacionadas às variações de matéria-prima (tipo e forma em que se encontram), método de extração e enzima utilizada.

\section{Conclusões}

O método enzimático de extração das proteínas da farinha comercial de arroz apresentou melhor desempenho ao se empregar a protease alcalina em relação à neutra. $\mathrm{O}$ estudo do efeito de diversos parâmetros mostrou que o emprego do tratamento físico da amostra não foi vantajoso para o REP, enquanto que a ação da temperatura, do $\mathrm{pH}$, da concentração da amostra e da relação E:S influenciaram de forma variada no REP. O melhor resultado $(63,4 \%)$ foi obtido ao se utilizar a concentração inicial de matéria-prima a 1:10 (p/v), sem tratamento físico, $\mathrm{pH}$ 10,5, com a protease alcalina na relação E:S de 10:100, a $50^{\circ} \mathrm{C}$.

\section{Agradecimentos}

Os autores agradecem à Fapemig, à CAPES e ao CNPq pelo apoio financeiro a este trabalho, nas formas de auxílio à pesquisa e bolsas de Mestrado e Iniciação Científica.

\section{Referências bibliográficas}

AGBOOLA, S.; NG, D.; MILLS, D. Characterization and functional properties of Australian rice protein isolates. Journal Cereal Science, v. 41, n. 3, p. 283-290, may. 2005.

ANSHARUllaH, J. A. H.; CHESTERMAN, C. F. Application of carbohydrases in extracting protein from rice bran. Journal of the Science of Food and Agriculture, v. 74, n. 2, p. 141-146, jun. 1997.

AOAC - ASSOCIATION OF OFFICIAL ANALYTICAL CHEMISTS. Official methods of analysis of AOAC international. 16 ed. Arlington: AOAC International, 1995. v. 2, 1141p.

BARATA, T. S. B. Caracterização do consumo de arroz no Brasil. In: CONGRESSO BRASILEIRO DE ECONOMIA E SOCIOLOGIA RURAL, 43, 2005, Ribeirão Preto. Anais... Ribeirão Preto, 2005. Disponível em: <http://www.arroz.agr.br>. Acesso em: 12 jul. 2005.

BIZZOTTO, C. S. et al. Hidrolisados protéicos de arroz com baixo teor de fenilalanina, obtidos pela ação da corolase PP e uso do carvão ativado. Ciência e Agrotecnologia, v. 30, n. 2, p. 308-316, mar./abr. 2006a.

BIZZOTTO, C. S. et al. Uso da pancreatina e do carvão ativado no preparo de hidrolisados protéicos de arroz com baixo teor de fenilalanina. Revista Tecno-Lógica, v. 10, n. 1, p. 9-30, jan./jun. 2006b.

BOBBIO, F. O.; BOBBIO, P. A. Introdução à química de alimentos. 2 ed. São Paulo: Varela, 1992. 222 p.

BRASIL. Resolução n ${ }^{\circ}$ 2, de 12 de março de 1978. Comissão nacional de normas e padrões para alimentos - CNNPA: aprova normas técnicas especiais relativas a alimentos e bebidas. Diário Oficial da República Federativa do Brasil, Brasília, DF, 24 jul. 1978, p. $11499-11528$. 
CAPOBIANGO, M. et al. Extração química e enzimática das proteínas do fubá de milho. Ciência e Tecnologia de Alimentos, v. 26, n. 4, p. 884-890, out./dez. 2006.

CHRASTIL, J. Correlations between the physicochemical and functional properties of rice. Journal of Agricultural and Food Chemistry, v. 40, n. 9, p. 1683-1689, sep. 1992.

CONNOR, M. A.; SAUNDERS, R. M.; KOHLER, G. O. Rice bran protein concentrates obtained by wet alkaline extraction. Cereal Chemistry, v. 53, n. 4, p. 488-496, jul./aug. 1976.

EUBER, J. R.; PUSKI, G.; HARTMAN JR., G. H. Method for making soluble rice protein concentrate and the product produced therefrom. United States Patent n. 4.990.344, feb. 5, 1991.

FISCHER, M. et al. Enzymatic extractability of soybean meal proteins and carbohydrates: heat and humidity effects. Journal of Agricultural and Food Chemistry, v. 49, n. 9, p. 4463-4469, sep. 2001.

FURLAN, E. F.; OETTERER, M. Hidrolisado Protéico de Pescado. Revista Ciência e Tecnologia, v. 10, n. 19, p. 79-89, jan./jun. 2002.

GUADIX, A. et al. Procesos tecnológicos y métodos de control en la hidrólisis de proteínas. Ars Pharmaceutica, v. 41, n. 1, p. 79-89, jan./mar. 2000.

HAGENIMANA, A.; DING, X.; FANG, T. Evaluation of rice flour modified by extrusion cooking. Journal of Cereal Science, v. 43, n. 1, p. 38-46, jan. 2006.

HAMADA, J. S. Characterization of protein fractions of rice bran to devise effective methods of protein solubilization. Cereal Chemistry, v. 74, n. 5, p. 662-668, sep./oct. 1997.

ILO, S.; LIU, Y.; BERGHOFER, E. Extrusion Cooking of Rice Flour and Amaranth Blends. Lebensmittel-Wissenschaft und-Technologie, v. 32, n. 2, p. 79-88, mar. 1999.

JU, Z. Y; HETTIARACHCHY, N. S.; RATH, N. Extraction, denaturation and hydrophobic properties of rice flour proteins. Journal of Food Science, v. 66, n. 2, p. 229-232, mar. 2001.

JULIANO, B. O. Rice in human nutrition. Rome: FAO, 1993. 168 p. Disponível em: <http://www.fao.org/inpho/content/documents// vlibrary/t0567e/T0567E00.htm>. Acesso em: 25 Jun. 2006.

LEHNINGER, A. L.; NELSON, D. L.; COX, M. M. Princípios de bioquímica. São Paulo: Sarvier, 1995. 761p.

LINDSAY, G. W.; SAUNDERS, R. M.; KOHLER, G. O. Protein concentrates from wheat shorts, rice bran, and soy flour by extraction with cheese wheys. Journal of Food Science, v. 42, n. 5, p. 1365-1369, sep./oct. 1977.

LUMDUBWONG, N.; SEIB, P. A. Rice starch isolation by alkaline protease digestion of wet-milled rice flour. Journal of Cereal Science, v. 31, n. 1, p. 63-74, jan. 2000.

MURTHY, K. V. R.; REY, L.; BELON, P. Photoluminescence and thermally stimulated luminescence characteristics of rice flour.
Journal of Luminescence, v. 122-123, n. 1, p. 279-283, jan./apr. 2007.

PIMENTEL-GOMES, F. Curso de estatística experimental. 14 ed. Piracicaba: Livraria Nobel S/A, 2000. 477p.

SGARBIERI, V. C. Proteínas em Alimentos Protéicos. São Paulo: Varela, 1996. 520p.

SHAW, J. F.; SHEU, J. R. Production of high-maltose syrup and high-protein flour from rice by enzymatic method. Bioscience Biotechnology Biochemistry, v. 56, n. 7, p. 1071-1073, jul. 1992.

$\mathrm{SHIH}, \mathrm{F}$. F. et al. Use of enzymes in the processing of protein products from rice bran and rice flour. Food/Nahrung, v. 43, n. 1, p. 14-18, jan. 1999.

SHIH, F. F.; DAIGLE, K. W. Use of enzymes for the separation of protein from rice flour. Cereal Chemistry, v. 74, n. 4, p. 437-441, jul./aug. 1997.

SHIH, F. F.; DAIGLE, K. W. Preparation and characterization of rice protein isolates. Journal of the American Oil Chemists' Society, v. 77, n. 8, p. 885-889, aug. 2000.

TANG, S.; HETTIARACHCHY, N. S.; SHELLHAMMER, T. H. Protein extraction from heat-stabilized defatted rice bran 1 - Physical processing and enzyme treatments. Journal of Agricultural and Food Chemistry, v. 50, n. 25, p. 7444-7448, dec. 2002.

USDA - United States Department of Agriculture. Human Nutrition Information Service. Agriculture Handbook. Composition of Foods: Cereal Grains and Pasta. Number 8-20, 1989. Modified From Drake, D.L., S.E. Gebhardt, R.H. Matthews. Updated: Friday, May 26, 2006. Disponível em: <http://food.oregonstate.edu/g/comp/ compa.html>. Acesso em: 08 jun 2006.

USP - Universidade do Estado de São Paulo. Tabela Brasileira de Composição de Alimentos, v. 4.1, 2004. Disponível em: <http:// www.fcf.usp.br/tabela/>. Acesso em: 22 jun 2006.

WANG, M. et al. Preparation and functional properties of rice bran protein isolate. Journal of Agricultural and Food Chemistry, v. 47, n. 2, p. 411-416, feb. 1999.

WANG, S. H.; FERNANDES, S. M.; CABRAL, L. C. Solubilidade de nitrogênio, dispersibilidade de proteína e propriedades emulsificantes dos extratos hidrossolúveis desidratados de arroz e soja. Ciência e Tecnologia de Alimentos, v. 20, n. 1, p. 12-17, abr. 2000.

WANG, L.; WANG, Y. J. Comparison of protease digestion at neutral $\mathrm{pH}$ with alkaline steeping method for rice starch isolation. Cereal Chemistry, v. 78, n. 6, p. 690-692, nov./dec. 2001.

WANG, L.; WANG, Y. J. Rice starch isolation by neutral protease and high-intensity ultrasound. Journal of Cereal Science, v. 39, n. 2, p. 291-296, mar. 2004a.

WANG, L.; WANG, Y. J. Application of high-intesity ultrasound and surfactants in rice starch isolation. Cereal Chemistry, v. 81, n. 1, p. 140-144, jan./feb. 2004b. 